\title{
INTRODUCING CLINICAL ETHICS CONSULTATION SERVICE TO KING FAHAD MEDICAL CITY IN RIYADH KINGDOM OF SAUDI ARABIA
}

\author{
Al-Kaabba A \\ Faculty of Medicine, King Fahad Medical City, King Saud University of Health Sciences, Riyadh, Saudi Arabia.
}

\begin{abstract}
:
As an integral part of medical ethics, it is important to have clinical ethics consultation services in our health care and hospitals. Such ethics consultations in health care settings are not a new idea with the first of such consultations dating back nearly 35 years to 1970. In the 1980s, a professional society devoted to ethics consultation was formed and the first books on the subject were published. There are few medical ethics specialists and only one bioethics department in Saudi Arabia. Therefore, ethics consultation services are not as organised as their counterparts in North America. Although many big hospitals in Saudi Arabia have medical ethics committees, these committees do not take care of clinical ethics consultation services. The goals of the present project is to start an ethics counsultation service through which we will introduce a good quality, fully integrated consultation ethics model. (JUMMEC 2010; 13(2): 88-92)
\end{abstract}

KEYWORDS: ethics consultation, medical ethics, Saudi Arabia

\section{Introduction}

As an integral part of medical ethics, it is important to have clinical ethics consultation services in our health care and hospitals. Such ethics consultations in health care settings are not a new idea with the first of such consultations dating back nearly 35 years to 1970. In the 1980s, a professional society devoted to ethics consultation was formed and the first books on the subject were published $(1,2,3)$. Circa mid-1990, a national consensus conference describing the goals of ethics consultation and methods for evaluating its quality and effectiveness was held and later in 1998, the Americal Society of Bioethics and Humanities (ASBH) published "Core Competencies for Health Care Ethics Consultation," a report that describes the proficiencies required for health care ethics consultation $(1,6)$.

Introducing effective clinical ethics consultation services to King Fahad Medical City (KFMC) in Riyadh in the Kingdom of Saudi Arabia, will not only improve health care quality in general, but will also: (a) promote practices consistent with high ethical standards; (b) be a good example to other clinical ethics consultation services in our area; (c) recognize participants' authority and values in the decision-making process; (d) educate participants in how to handle current and future medical ethical concerns; (e) improve and support medical ethics committee services; and (f) support patients' education about ethics and their rights.

There are few medical ethics specialists and only one bioethics department in Saudi Arabia, therefore ethics consultation services are not as organised as their counterparts in North America. Although many big hospitals in Saudi Arabia have medical ethics committees, these committees do not take care of clinical ethics consultation services. The goals of the present project is to start an ethics consultation service

Correspondence:

Abdul Aziz Al-Kaabba

Faculty of Medicine, King Fahad Medical City

King Saud University of Health Sciences

PO Box 59046

Riyadh, Saudi Arabia

Email aalkaaba@kfmc.med.sa 
through which we will introduce a good quality, fully integrated consultation ethics model.

\section{Ethics consultation in healthcare}

In health care, we define ethics consultation as a service provided by an individual ethics consultant, an ethics consultation team, or an ethics committee to help patients, providers, and other parties resolve ethical concerns within a health care setting (1).

This consultation is now widely recognized as an essential part of health care delivery. The Joint Commission for Accreditation of Healthcare Organizations requires hospitals to develop and implement a process to handle ethical concerns when they arise. $(1,4)$ In addition, the Malcolm Baldrige National Quality Award Program recognises "ethical behavior in all stakeholder transactions and interactions" as a key criterion for performance excellence (5).

There many international and national studies devoted to ethics consultation services many of which are concerned about ethics consultation services related to patient and families. For example, a study done to determine patients and their families satisfaction with ethics consultation and the treatment decisions that resulted from them found that patients and families, based on an analysis of their comments, found ethics consultation provided by clinical ethicists at Loma Linda University Medical Center to be helpful in a majority of instances, and rarely found them detrimental (6).

Another study done on the utilization and evaluation of ethics consultation services in a teaching hospital by La Puma and co-workers (7) evaluated a newly established formal ethics consultation service in a university teaching hospital prospectively. A physician-ethicist interviewed and examined patients, family and others as needed before entering a formal consultation note in the medical record. Requesting physicians stated that the consultation was very important in patient management, in clarifying ethical issues, and in learning about medical ethics leaving us to conclude that the ethics consultation performed by physician-ethicists provides useful, clinically acceptable assistance in a teaching hospital (7). Another study from St. Joseph's Hospital, in
Hamilton, Ontario by Coughlin and Watts surveyed demographics, educational background, time spent on ethics, institutional affiliations, approaches to the role of consultation, research related issues, and attitudes toward ethics consultation. The conclusion supported ethics consultation services. Additionally this survey was used as a reference point for studying the roles, responsibilities, training and accreditation of ethics consultants in health care (8).

\section{Background about the King Fahad Medical City}

KFMC (9) is a big medical specialist city located in the center of Riyadh in the Kingdom of Saudi Arabia. It is under the umbrella of the Ministry of Health $(\mathrm{MOH})$. Opened in 2005, the new medical city has 1200 beds and includes four major hospitals: general, children, maternal and rehabilitation, as well as four specialized medical centers in oncology, neurology, cardiology, and the intensive care unit. There is also a modern medical college where a new bioethics department, which will support the ethics consultation project, is located. The budget for this medical city is around 300 million US dollars per annum with around 4,000 employees working in the city. There is an ethics committee in the hospital, but there is a need to introduce the ethics consultation services. Therefore, the aim of this paper is to show the necessity of having clinical ethics consultations.

\section{Proposed models of ethics consultation services at KFMC}

We will use the ethics consultation team model because it is practical and is a compromise between the individual and committee model. In this model, the responsibility for giving an ethics consultation is shared by many groups like a small group of qualified consultants with expertise in such circumstances. There are many advantages and few disadvantages to this model. It supports flexibility for rapid response and support as well as a diversity of expertise. Also it is less intimidating than the committee model for patients and family and allows for the composition of the team to vary to meet the situation. Unfortunately, this model is less efficient than the individual consultant model because in this model, a single member may perform both rules and then report back to the other on the team. 
To combat this issue, our team will include members from both the medical and academic staff who are experts in medical ethics. Also included are members of the nursing staff and we may take a family member on our team that will give us good support.

Since this project is the beginning of ethics consultation services in KFMC, the process will start off with just clinical ethics consultation for medical staff in the first six months. Later, the services will be introduced to all the hospitals, patients and their families. This plan will depend both on the ethics consultation committee's support and the senior academic staff from the medical college, which will provide leaders and senior staff. In the following year, the plan to introduce ethics education and training will be implemented.

Ethics consultation services will cover all hospitals and clinical centers including, but not limited to ICU, $\mathrm{CCU}$, oncology, neurology, psychiatry, and geriatric medicine. Also, ethical consultation service processes will cover all referral cases related to medical ethics policy making and forms.

\section{Ethics consultation approach and tools}

The National Center for Ethics in Health Care designed the CASES approach to standardize the process of ethics consultation throughout the VA system. The CASES acronym stands for:

Clarify the consultation request.

Assemble the relevant information.

Synthesize the information.

Explain the synthesis.

Support the consultation process.

For consultations involving active clinical cases, consultants should follow all the steps in the CASES approach. For other types of consultations, such as general questions about ethics, policy interpretations, or requests for ethical analysis of organizational ethics topics, the CASES approach should be modified as needed (1-2). The CASES steps were initially designed to guide ethics consultants through the complex processes needed to effectively resolve ethical concerns in active clinical cases and is therefore both practical and ethical to our purposes.
Clarifying the consultation request involves the characterisation of the type of consultation request, obtaining preliminary information from the requester, and establishing realistic expectations about the consultation. Assembling the relevant information involves considering the types of information needed and identifying the appropriate sources of information. This information may be obtained from the patients, their health records, staff and family members. Gathering information systematically from each source should be done accurately and professionally. Summarizing the consultation and the ethics question is an important step. Synthesising the information may require determining whether a formal meeting is needed. The ethical issues are then analysed critically using one of the approaches to ethical analysis, such as principalism (10), which describes four principlesautonomy, beneficence, non-malfeasance and justice and casuistry. It is also necessary to identify the ethically appropriate decision maker and facilitate moral deliberation. This step is impotent because of the need to know who is the real decision maker. The synthesis must be explained and must be communicated to key participants. Additional resources are provided and the consultation is documented in the health record. The consultation process is supported by follow-up with participants and evaluating the consultation. It can be adjusted and underlying issues can be determined (1).

\section{Success factors and challenges}

A consultation service must have integration with leadership support. Expertise, staff time, resources, access, accountability, organizational learning, and evaluation are additional factors that should be ensured. Because all these factors are critical for the success of ethics consultation services, it is important to take these factors and challenges in our consideration.

Several factors are critical for the success of the services. First, knowledge and skills. We have a good team composed of experts who are not only qualified to run these services, but has expertise in many ethical issues and concepts in the area of medical ethics. Two of the team members even have medical ethics qualifications from the United States. We have a good healthcare environment that supports these services and KFMC has strong leadership support from higher hierarchies. The team will also include expert staff on medical ethics consultation services 
and will have adequate staff time because some of them are already members of the ethics committee in the hospitals. The leaders will support adequate staff time for ethics consultation activities. In our plan, these ethics consultation services will be accessible to the patients, families, and staff, as well as to in-patients clinical setting and for homecare and long term care later in the second phase. In the beginning, the ethics consultation services will be available only during normal work hours, but weekends will be phased in later. One of the important supportive issue to these services will be the new department of bioethics in our medical college, which was approved by the CEO of KFMC and the Dean of the medical college. This will both aid in the integration and support of the ethics consultation services in the hospitals.

We will have some challenges and difficulties because this is the first ethics consultation service that will be opened in the $\mathrm{MOH}$. One of the bigger ones will be from the patients themselves and their families especially in the critical care units but that will be solved by our policies and regulations. Another challenge will be the lack of qualified staff specialized in medical bioethics, but we believe that our other expert staff with their qualifications in other fields will remedy that. Resource allocations (budget of these services) in the first year will also be an issue. We will apply the "accountability for reasonableness" models (A4R) for resource allocation.

\section{Evaluation of the consultation services}

Because evaluation of our ethics consultation services in KFMC will be one of the priorities, there will be systematic assessments of the operation and outcomes of our ethics consultation services. Initially, this will occur biannually, but will gradually be phased into an annual process. Our tool will be the Ethics Consultant Proficiency Assessment Tool (11). This assessment tool is designed to help individuals assess their proficiency level with respect to the skills and knowledge required to provide competent health care ethics consultation.

Before the evaluation we will make sure that there is an organization chart, plan and policy of our ethics consultation services. The evaluation will systematically assess the ethics consultation proficiency assessment tool (this tool is based on a report from the ASBH (12).
The responsibility for this evaluation will fall to the ethics consultation coordinator along with assessment of integration, leadership support, expertise, staff time, resources, access, accountability, organizational learning and policy structure, and function processes of the ethics consultation. Finally, the assessment should include the performance of approach to ethics consultation (CASES) and whether or not the ethics consultation services is meeting its professed goals.

\section{Conclusion}

Ethics consultation is an important service that helps to ensure the quality of ethical practices and patient care. By providing clinical ethics consultation services in KFMC, the quality of health care will definitely improve and we expect good support in introducing ethics consultation services in KFMC. We will use ethics consultation team model with CASES approach. Annual evaluations of this ethics consultation services in KFMC will be followed and the ethics consultation proficiency assessment tools will be used.

\section{References}

1. Anonymous. Ethics Consultation.Integrated Ethics Veterans Administration. pages 1-54.

2. Cranford RE, Doudera AE, eds Institutional Ethics Committees and Health Care Decision Making. Ann Arbor, Ml: Health Administration Press; 1984.

3. Fletcher JC, Quist N, Jonsen AR, eds. Ethics Consultation in Health Care. Ann Arbor, MI: Health Administration Press; 1989.

4. Joint Commission on Accreditation of Healthcare Organizations. Standard RI.1.10. Comprehensive Accreditation Manual for Hospitals: The Official Handbook. Oakbrook Terrace, IL: Joint Commission on the Accreditation of Healthcare Organizations; 2006.

5. 2006 Health care criteria for performance excellence. Available from http://www.baldrige. nist.gov/PDF_files/2006_HealthCare_Criteria.pdf;. Accessed 20 Nov 2006.

6. American Society for Bioethics and Humanities, Task Force on Standards for Bioethics and Consultation. Core Competencies for Health Care 
Ethics Consultation: The Report of the American Society for Bioethics and Humanities. Glenview, IL: American Society for Bioethics and Humanities; 1998.

7. La Puma J, Stocking CB, Darling CM, et al. An ethics consultation service in teaching hospital, utilization and evaluation. Am J Med 1992 Apr;92(4): 346-351.

8. Coughlin MD, Watts J St. Joseph's Hospital, Hamilton, Ontario. HEC Forum. 1993 May; 5(3): 144164.

9. Faculty of Medicine, King Fahad Medical City. Available from http://www.kfmc.med.sa. Accessed 20 Sept 2009.

10. Beauchamp TL, Childress JF. Principles of Biomedical Ethics, 5th Ed. New York: Oxford University Press; 2001.

11. Anonymous. Ethics Consultation Toolkit. Integrated Ethics,. Veteran's Administration

12. This tool is based on a report from the American Society for Bioethics and Humanities (ASBH) entitled Core Competencies for Health Care Ethics Consultation (1998). 